\title{
Large-scale decline in offshore seagrass meadows in Bermuda
}

\author{
T. J. T. Murdoch ${ }^{1, *}$, A. F. Glasspool ${ }^{1}$, M. Outerbridge ${ }^{1}$, J. Ward ${ }^{2}$, S. Manuel ${ }^{2}$, J. Gray ${ }^{2}$, \\ A. Nash $^{2}$, K. A. Coates ${ }^{1,2}$, J. Pitt ${ }^{3}$, J. W. Fourqurean ${ }^{4}$, P. A. Barnes ${ }^{5}$, M. Vierros ${ }^{6}$, \\ K. Holzer ${ }^{3,7}$, S. R. Smith ${ }^{3,8}$ \\ ${ }^{1}$ Bermuda Zoological Society, PO Box FL 145, Flatts, FL BX, Bermuda \\ ${ }^{2}$ Bermuda Ministry of the Environment, Department of Conservation Services, PO Box FL 588, Flatts, FL BX, Bermuda \\ ${ }^{3}$ Bermuda Institute of Ocean Sciences, 17 Biological Lane, St George's, GE 01, Bermuda \\ ${ }^{4}$ Florida International University, Department of Biological Sciences, 11200 SW 8th Street, Miami, Florida 33199, USA \\ ${ }^{5}$ Malaspina University, 900 Fifth Street, Nanaimo, British Columbia N9R 5S5, Canada \\ ${ }^{6}$ Secretariat of Convention on Biological Diversity, World Trade Center, 393 Saint Jacques Street, Suite 300, \\ Montreal, Quebec H2Y 1N9, Canada \\ ${ }^{7}$ University of Virginia, Department of Environmental Sciences, 219 McCormick Road, Charlottesville, Virgina 22904, USA \\ ${ }^{8}$ Georgia State University, Department of Biology, PO Box 4010, Atlanta, Georgia 30303, USA
}

\begin{abstract}
Bermuda is an isolated 5560 ha chain of limestone islands on a 150000 ha seamount located near $32^{\circ} \mathrm{N}, 64^{\circ} \mathrm{W}$. Meadows of tropical and subtropical seagrasses, dominated by Thalassia testudinum and Syringodium filiforme, are found from inshore bays out to the inner edge of the rim reef that encircles the platform. Fine-scale computerized mapping and subsequent broad-scaled field assessment of seagrass meadows in Bermuda show that (1) meadows representing nearly one-quarter of the territory's total seagrass area in 1997 had declined by 2004, (2) net loss of seagrass meadows occurred at rim reef and lagoonal locations that are far-removed from anthropogenic disturbances, (3) the decline appears to have been in progress as early as 1996, and (4) both T. testudinum and $S$. filiforme meadows declined. Nearly 2100 ha of meadows were visible in a 1997 georeferenced mosaic of aerial photographs of the Bermuda platform. In 2004, 22 meadows that represented about 475 of the 900 ha of offshore seagrass identified in 1997 and earlier were absent or in obvious decline. The size and location of inshore and nearshore meadows, which are exposed to intense anthropogenic stresses and physical damage, varied over the same 7 yr but their total area has either remained unchanged or even increased. Processes contributing to the decline in offshore meadows have yet to be determined, but may include herbivory by juvenile green turtles and parrotfishes and below-normal productivity owing to a winter cold-water event correlated with a change in the North Atlantic Oscillation (NAO) in 1996. The potential consequences to Bermuda of the loss of nearly 500 ha of critical marine habitat are of extreme concern.
\end{abstract}

KEY WORDS: Benthic habitat mapping • Environmental monitoring - Thalassia testudinum • Syringodium filiforme $\cdot$ Seagrass die-off $\cdot$ Herbivory

\section{INTRODUCTION}

Bermuda is a 5560 ha chain of limestone islands located in the North Atlantic near $32^{\circ} \mathrm{N}, 64^{\circ} \mathrm{W}$. The islands run along the southeast side of a 150000 ha, shallow and atoll-like coral reef platform accreted on the top of an eroded volcano formed over 33 million yr ago. Arrays of patch reefs and reef flats extend from nearshore, across the deeper lagoon situated to the north and west of the islands, and out to the rim reef that encircles the platform. Beyond the rim in all directions is a $1 \mathrm{~km}$ wide forereef terrace that reaches 
to $50 \mathrm{~m}$ depth. Offshore of this terrace, the sides of the seamount slope down precipitously to $1000 \mathrm{~m}$ depth and then gradually to the seafloor at $4500 \mathrm{~m}$. Bermuda's prevailing warm oceanic conditions support a limited number of small mangrove forests, extensive and healthy coral reefs, as well as meadows of tropical and subtropical seagrasses, all of which are at the northern limits of their distribution in the Atlantic.

Four species of seagrass are found in Bermuda: Thalassia testudinum Banks \& Solander ex König (turtle grass), Syringodium filiforme Kuetzing (manatee grass), Halodule wrightii Ascherson (shoal grass), and Halophila decipiens Ostenfeld (paddle grass). Bermuda is the northern geographic limit for T. testudinum, $S$. filiforme, and $H$. decipiens in the Atlantic (South 1983), whereas $H$. wrightii occurs in slightly more northern, continental locations (Thayer et al. 1984). In Bermuda, T. testudinum, $S$. filiforme and H. wrightii are limited to depths $<12 \mathrm{~m}$ (T. Murdoch, S. Manuel \& A. Glasspool unpubl. data) and thus do not grow across the deeper parts of the inshore basins or across the floor of the lagoon. Halophila decipiens is able to grow at lower light intensities (Durako et al. 2003), and is patchily distributed across the platform to depths $\leq 18 \mathrm{~m}$ (K. Coates \& S. Manuel unpubl. data).

Globally, seagrass-dominated habitats are recognized as productive ecosystems with elevated and unique biodiversity. They play vitally important roles in the cycling of nutrients and provide structural integrity to shallow marine areas (cf. Larkum et al. 2006). Owing to the limited extent of mangroves in Bermuda (17.49 ha total area, Anderson et al. 2001), Bermuda seagrass meadows represent the primary habitats for a number of juvenile fishes (Glasspool 1994). They are also primary developmental habitat for species of interest and concern, such as lobsters, conchs, and green turtles (Evans \& Evans 1995, Berg et al. 1992, Meylan et al. 1998).

In 2004 the Bermuda Reef Ecosystem Assessment and Mapping (BREAM) programme - a collaboration of the Bermuda Biodiversity Project and the Bermuda Ministry of the Environment, Department of Conservation Services - undertook the first project to map and evaluate the ecological condition of all seagrass habitat country-wide, using aerial photography, geographic information system (GIS) protocols and an hypothesisdriven in situ assessment program. The primary objective of the BREAM project was to create 'groundtruthed' baseline maps, an ecological database, and comprehensive reports regarding the territory's seagrass distribution and condition against which future and past habitat maps or research could be compared, in order to provide guidance for scientific research and local resource management.
Here we document evidence of the decline in condition of many large seagrass meadows in Bermuda, along with the results of several unpublished studies that provide supplementary information regarding the environmental, biological and anthropogenic causes and characteristics of these habitat changes. Precise mapping of fine-scale changes in seagrass meadow boundaries over time is ongoing.

\section{MATERIALS AND METHODS}

Digital mapping of seagrass habitat. In June 1997 a geo-referenced series of aerial photographs of the Bermuda islands and surrounding submerged platform was acquired (Fig. 1). The images were subsequently scanned and a composite raster bitmap for the entire Bermuda platform was produced, with a final resolution of $50 \mathrm{~cm}$ per pixel and a geo-referenced error of $<2 \mathrm{~m}$ (Bermuda Zoological Society 1997). The 1997 aerial survey had 2 phases: a terrestrial survey flown at $1524 \mathrm{~m}$, providing photographs at 1:10 000 of the nearshore marine areas, and a marine survey to the $20 \mathrm{~m}$ depth contour flown at $4572 \mathrm{~m}$, providing photographs at a 1:30000 scale. A Zeiss Jena LMK photogrammetric survey camera with forward motion compensation was used for both phases of the survey. The photographic system was equipped with real time data projectors to print the geographic position and time on the side of each exposure. The aircraft was also equipped with an Accuphoto GPS flight management system to provide accurate geo-referencing of marine photographs, which lack control points of known location and elevation. An interface relayed the mid-point of the exposure signal to the GPS event marker logger, allowing for precise location of the perspective centre at the instant of exposure. This survey was conducted with $80 \%$ forward and $30 \%$ lateral overlap of neighbouring photographs.

A preliminary map of probable seagrass habitat was then created for the entire Bermuda platform from the digital mosaic with the GIS package ESRI ArcMap 9.1, with the marine areas largely derived from the 1:30 000 scale photographic images. The boundaries of seagrass areas were digitized manually by a single operator as continuous closed polygons within a polygon layer of ArcMap, at a scale of 1:2500. Key characters that were assessed in the discrimination of seagrasses from adjacent habitats were: colour (light to dark greenish-gray); presence of sand halos around reefs or produced by mooring chains; and crescent-shaped sand blowout holes. The spatial area of each seagrass polygon was subsequently calculated by the ArcMap software.

As the criterion of color was used to delimit these boundaries, very sparse $\left(<25\right.$ blades $\left.\mathrm{m}^{-2}\right)$ seagrass 


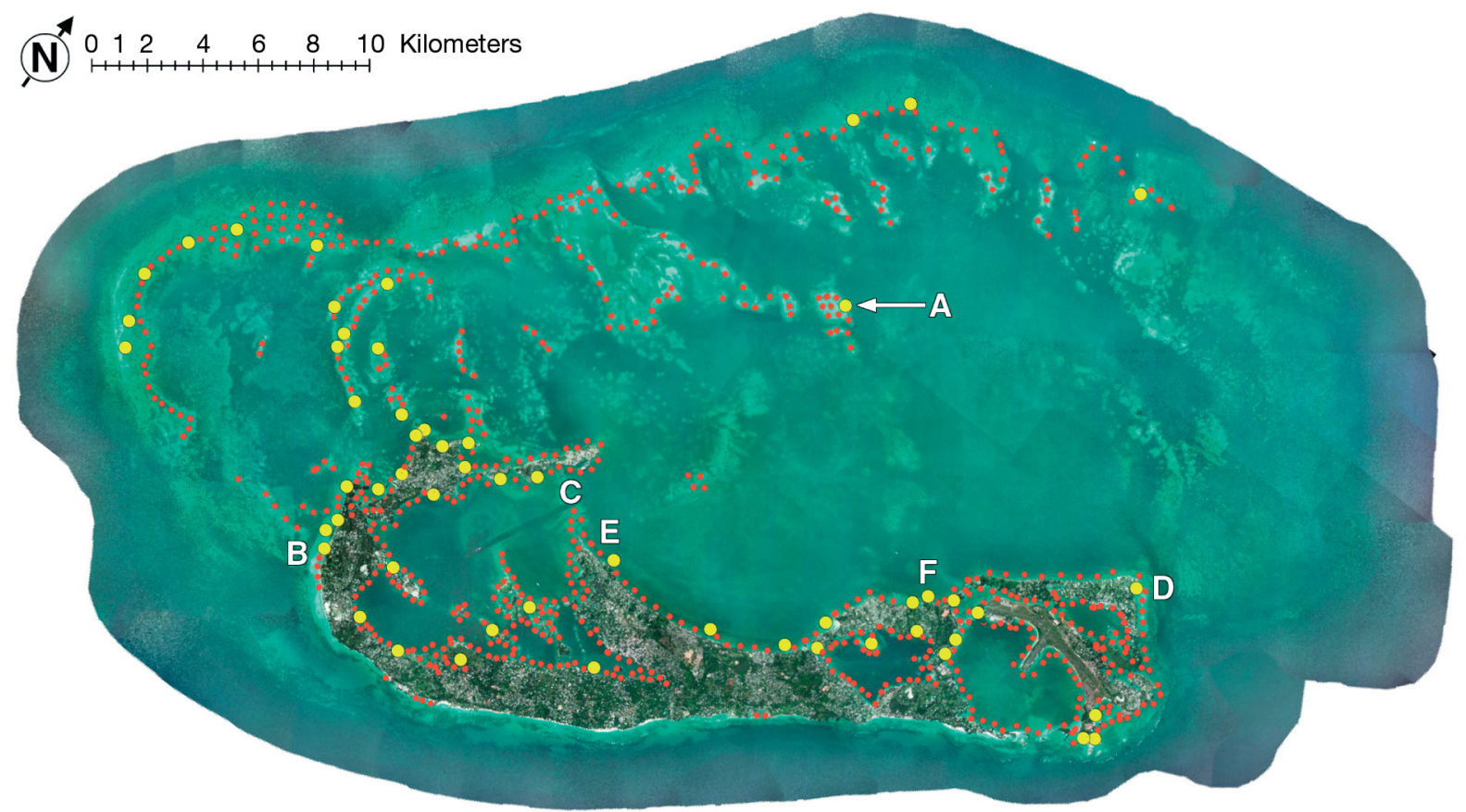

Fig. 1. Aerial mosaic map of islands and surrounding lagoonal platform of Bermuda (ca. $32^{\circ} \mathrm{N}, 64^{\circ} \mathrm{W}$ ). Dots represent sites surveyed for the presence and condition of seagrass using Level 1 (red) and Level 2 (yellow) assessment protocols. A: Crescent Reef; B: Tudor Hill; C: Great Sound; D: Fort St. Catherine; E: Spanish Point; F: Bailey's Bay (Copyright 1997, 2005 Bermuda Zoological Society)

areas were not classified in these images. The type and quality of mapping information was similar for each area, so that the degree of error in determining meadow boundaries and the associated error of these estimates was consistent across the platform. Spatial referencing was accurate to $2 \mathrm{~m}$ and, combined with a pixel size of $50 \mathrm{~cm}$, allowed a spatial accuracy of about $\pm 2.5 \mathrm{~m}$ for seagrass boundaries. The thematic accuracy of the habitat map was determined by field assessments and by comparisons with other mapping studies, as described below.

Field assessment of seagrass meadows. In order to verify the presence, species composition, and ecological condition of seagrass meadows mapped from the 1997 photomosaic, along-track surveys that encompassed the Bermuda platform were conducted by BREAM from May to September 2004. All sandy areas within $15 \mathrm{~m}$ depth were visited and assessed for the presence of seagrass meadows using either of 2 protocols (Fig. 1). For Protocol 1, each survey site was located by GPS or from landmarks that could be seen in the aerial mosaic image, and all survey site data were entered into the GIS system. Meadow presence, species composition, and the average condition of seagrasses on a 4-point scale was confirmed by 150 rapid visual assessments, obtained via use of glass bottom buckets and snorkel (0: absent; 1 : exceptionally sparse; 2: sparse; 3: dense seagrass, blades overlapping, substrate not visible). If no extant shoots were found at a site, the prior presence of seagrass was assessed by digging into the sediment for Thalassia testudinum rhizomes. Rhizomes have been found to persist in areas of drastically declining meadows for at least $7 \mathrm{yr}$ in Bermuda (T. Murdoch pers. obs.).

In addition, 55 comprehensive, in situ Protocol 2 surveys using SCUBA were made by BREAM to further assess seagrass meadow condition across 4 physiographic zones of the reef platform. The inshore zone consisted of bodies of water enclosed by land. The nearshore zone encompassed marine habitat located within $500 \mathrm{~m}$ of the shore. The lagoonal zone included habitats located further than $500 \mathrm{~m}$ from shore but within $500 \mathrm{~m}$ of the shallow rim reef that encircles the Bermuda Platform. The offshore zone represented areas located within $500 \mathrm{~m}$ of the inner edge of the shallow rim. During the comprehensive surveys, a range of biological and ecological data on any present seagrass, fish and other biota and the environmental conditions of each site was collected. These data included an evaluation of \% cover by seagrasses on the same 4-point scale as above, shoot density counts and seagrass height measurements in 35 quadrats with dimensions of $25 \times 25 \mathrm{~cm}$, regularly spaced over an $8 \times 35 \mathrm{~m}$ area on a $5 \times 7$ point grid. For the results reported in this study, data from the comprehensive surveys are used simply to verify the presence and density rating of seagrass meadows. 
Nearshore seagrass dynamics over time. Ward (1999) assessed fine-scale changes to the extent of nearshore seagrass habitat from aerial photographic surveys collected in 1962, 1973, 1981, and from the same 1997 photomosaics used in the current study. The 1973 and 1997 photomosaics can be viewed at www.bermudamaps.bm. The quality of the images and completeness of the series improved with time. Both 1:10 000 scale and 1:30 000 scale images from the 1997 series were used, depending on glare from the water surface, which was a particular problem with the 1:10000 series. Documentation of the aerial surveys used by Ward (1999) for dates prior to 1997 is incomplete, including particulars of the planes and photographic equipment employed. However, the earlier surveys were all flown at $1524 \mathrm{~m}$ and the photographs provided at a scale of 1:10000. All earlier series appeared to be photographed with $60 \%$ forward overlap and either 10 or $20 \%$ lateral overlap. The 1981 series provided the most complete coverage of inshore marine features at a scale of 1:10000.

Mapping from the aerial photographs was done by directly tracing the boundaries of seagrass meadows seen in the 1981 photographic series onto a Bermuda map, scale 1:10 560 (Series E8110, Edition 2-Bda 1975, Public Works Department, Bermuda). Photographs and the map were rectified by overlapping prominent geographical features. Once the outlines of the seagrass meadows had been drawn, a planimeter was employed to estimate the areas of the irregularly shaped meadows. An estimate of the error of the planimeter method was made by repeatedly measuring particular grass meadows, both from mapped boundaries and directly from photographs. Error values ranged from $\pm 0.0014 \mathrm{~km}^{2}$ to $\pm 0.0050 \mathrm{~km}^{2}$ and were considered to be within acceptable limits (Ward 1999).

Separately, assessments of the extent of nearshore seagrass habitat in the BREAM field studies of 2004 were qualitatively compared with the results from earlier studies of the same ecological zone by Ward (1999). This comparison evaluated large-scale changes in the presence or absence of seagrass meadows rather than small-scale changes to meadow boundaries.

Offshore seagrass dynamics over time. Short-term changes in Thalassia testudinum green leaf, short shoot and rhizome biomass were quantified at 2 sites within a single outer lagoon location from 1993 to 1999, as part of Bermuda's Caribbean Coastal Marine Productivity Program (CARICOMP) project (Smith 1998, CARICOMP 2004). Each $100 \mathrm{~m}^{2}$ site was located in sandy substrate at a depth of $6 \mathrm{~m}$, and enclosed within a $1 \mathrm{~km}$ diameter mini-atoll coral reef surrounded by the $17 \mathrm{~m}$ deep water of the North Lagoon (Crescent Reef, Fig. 1). Both sites were surveyed once or twice yearly from 1993 to 1999 using standard methods (Smith 1998, CARICOMP 2004).
The northern Crescent CARICOMP site was also included in the BREAM comprehensive field surveys in 2004. In addition, qualitative assessment of the condition of the seagrass meadow at the northern Crescent CARICOMP site was conducted by the Bermuda Turtle Project (BTP) during 1992 to 2006, using the same 4-point scale described above.

Estimation of grazing intensity. Estimates of the intensity of parrotfish grazing were compared among physiographic zones at 5 inshore, 10 nearshore and 5 offshore sites on August 28, 2005, following the methods described by Kirsch et al. (2002). At each site a snorkeller haphazardly collected 20 or more Thalassia testudinum blades within a period of $3 \mathrm{~min}$. Once on the boat, all leaves were examined for evidence of parrotfish grazing based on the presence of a clearly observable crescent-shaped bite mark. The percentage of bitten blades relative to the total number of collected blades was calculated for each site, and the average estimate of grazing intensity was calculated for each habitat type. Grazing intensity data collected from each physiographic zone in the Bermuda region were also statistically compared with data collected from nearshore and back-reef environments of the Florida Keys, USA, using 1-way ANOVA (Kirsch et al. 2002).

\section{RESULTS}

Comparisons of the BREAM field assessments of 2004 with the habitat map created from the 1997 aerial mosaic determined that a total of 475 ha of seagrass meadows located in the lagoonal and rim reef zones had dramatically deteriorated in density or been totally lost (Fig. 2). The map created from the 1997 digitized aerial photomosaic encompassed a total area of 2100 ha of seagrass, with $\sim 1200$ ha in inshore and nearshore locations, and $\sim 900$ ha in lagoonal and rim reef locations. The field surveys of 2004 located only $\sim 1625$ ha of seagrass habitat. The remains of a Thalassia testudinum rhizosphere, but no extant seagrass, were found in 2004 at a number of locations where sparsely or densely foliated (i.e. a score of either 2 or 3 ) seagrass meadows were recognized in the images of 1997. In total 22 meadows, primarily in lagoonal and offshore areas (Fig. 2), were either completely absent (0) or had declined to a very sparse condition (1).

\section{Nearshore seagrass dynamics}

The analysis by Ward (1999) determined that, although specific seagrass meadows changed in area in the photomosaics spanning from 1962 to 1997, the total area of nearshore seagrass meadows remained 


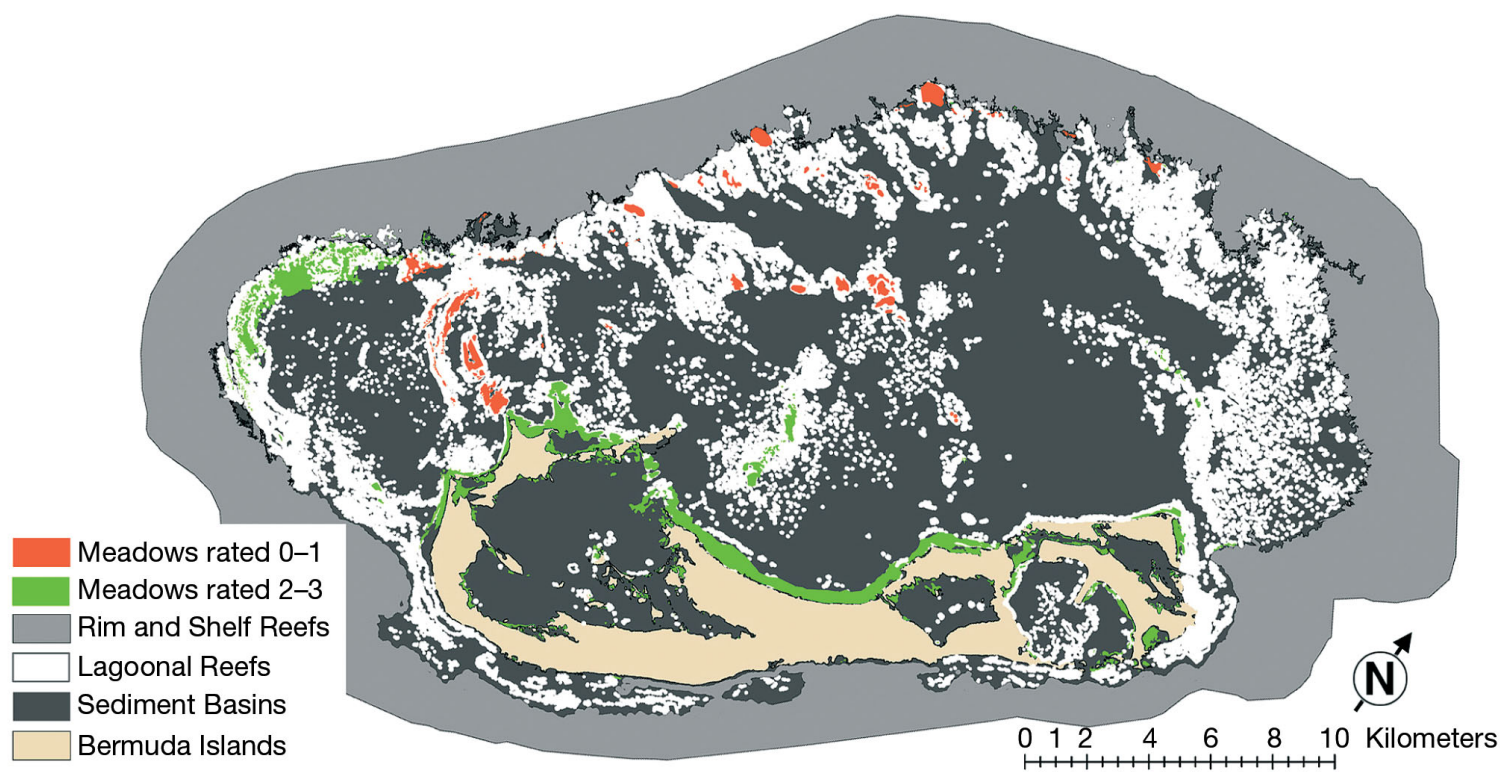

Fig. 2. Islands and reef platform of Bermuda (ca. $32^{\circ} \mathrm{N}, 64^{\circ} \mathrm{W}$ ), showing extent of seagrass meadows in the summer of 2004 (green) and area lost since 1997 (red). Copyright 1997, 2005 Bermuda Zoological Society

quite constant at $\sim 500$ ha over the 35 yr period. Specifically, a seagrass meadow located near Tudor Hill decreased from 53.2 ha in 1981 to 31.9 ha in 1997; a meadow at the mouth of Great Sound decreased from 26 ha in 1981 to 7.7 ha in 1997; and a meadow near Fort St. Catherine declined in area from 20 ha in 1962 to 7.7 ha in 1997 (Fig. 1). However, these loses were offset by significant gains in the extent of other large inshore meadows over the same period (Ward 1999). For example, a patchy collection of primarily Syringodium filiforme seagrass meadows along the north shore of the largest island coalesced into 1 continuous meadow that extended from Spanish Point to Bailey's Bay, representing an increase in area from 96 ha to 316 ha. In other meadows, both expansion and contraction could be detected over the period from 1962 to 1997, resulting in little overall change in extent.

\section{Offshore seagrass dynamics over time}

At the Crescent CARICOMP sites, the green leaf, short shoot and rhizome components of above- and below-ground biomass of Thalassia testudinum showed annual fluctuations from 1993 to 1996 (CARICOMP 2004; Fig. 3). However, in 1997 the biomass of green leaves dropped dramatically, and by 1998 virtually no green leaf biomass remained. Belowground biomass also demonstrated reductions by 1998 (Smith 1998). In 1999 and 2000 respectively, seagrass monitoring was abandoned at the southern and northern Crescent sites, because no green leaves could be observed after extensive searching at each site, which meant production and leaf biomass were no longer measurable.

The change in condition of the northern seagrass meadow at Crescent Reef was also documented in the repeated observations of the BTP using the 4-point density described above in 'Field assessments of seagrass meadows' (Fig. 4). In 1992 the shoots of the seagrass meadow were characterized as 'dense'; by 1998 the shoots appeared 'sparse', and in 2004 shoots were completely absent and remained so in 2005 and 2006. Similarly, in 2004 the detailed investigation of the northern Crescent site by BREAM found no seagrass in any of 35 quadrats, while a layer of dead Thalassia testudinum rhizomes could be found by digging a trench 15 to $30 \mathrm{~cm}$ into the sediment. It appears that a precipitous decline in this lagoonal seagrass habitat occurred between 1996 and 1998, and there continues to be no signs of meadow redevelopment at the offshore site.

\section{Estimates of grazing intensity}

Total frequency of parrotfish herbivory at all sites in Bermuda was significantly greater $(p<0.01)$ than in the Florida Keys, with a mean of $58 \%( \pm 16 \mathrm{SE})$ of seagrass blades across all sampling locations showing signs of consumption, compared with a mean frequency of $33 \%( \pm 28 \mathrm{SE})$ herbivory in the Hawks Channel region of Florida (Kirsch et al. 2002; Fig. 5). Herbivory rates in Bermuda appeared higher at offshore sites than at inshore or nearshore sites; however, the differences were not statistically significant ( $p=0.243$ ). 

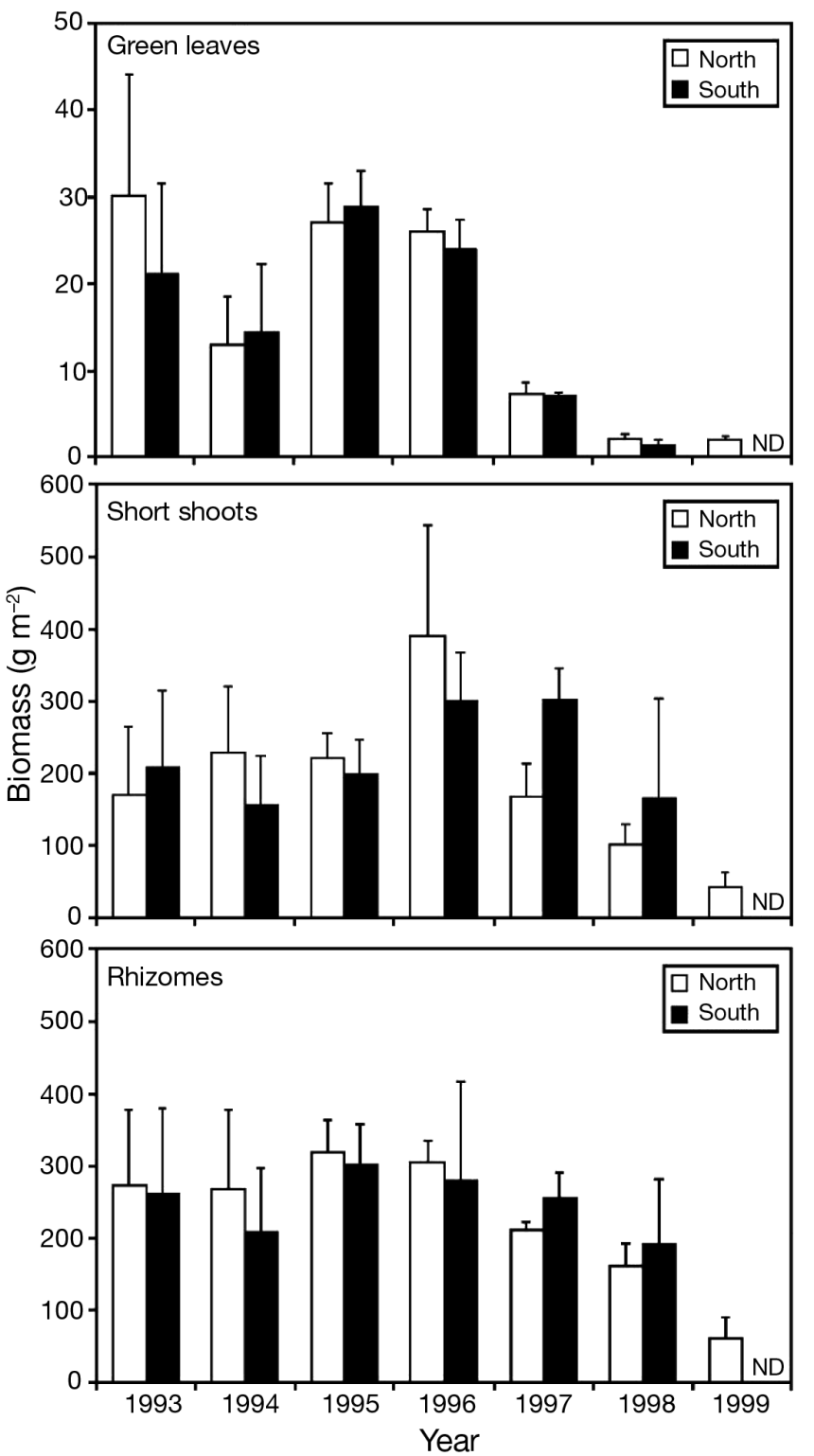

Fig. 3. Thalassia testudinum. Changes in above- and belowground biomass (mean $\pm \mathrm{SE}$ ) at the northern and southern CARICOMP sites at Crescent Reef from 1993 to 1999. ND: no data

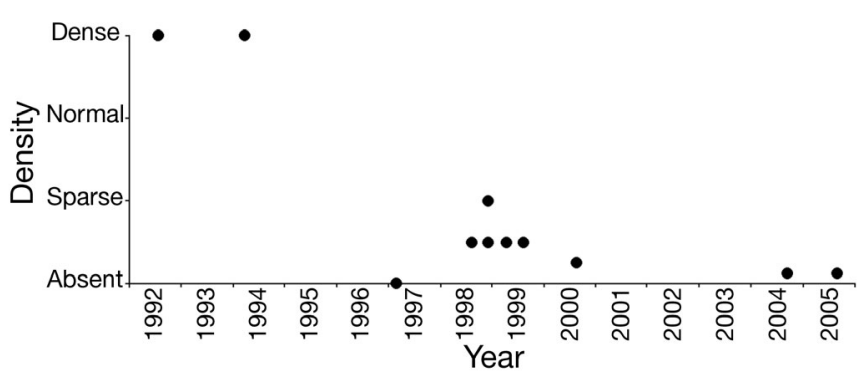

Fig. 4. Qualitative changes in seagrass meadow density at the northern CARICOMP site at Crescent Reef from 1992 to 2005, based on comments logged during sampling trips of the Bermuda Turtle Project (BTP)

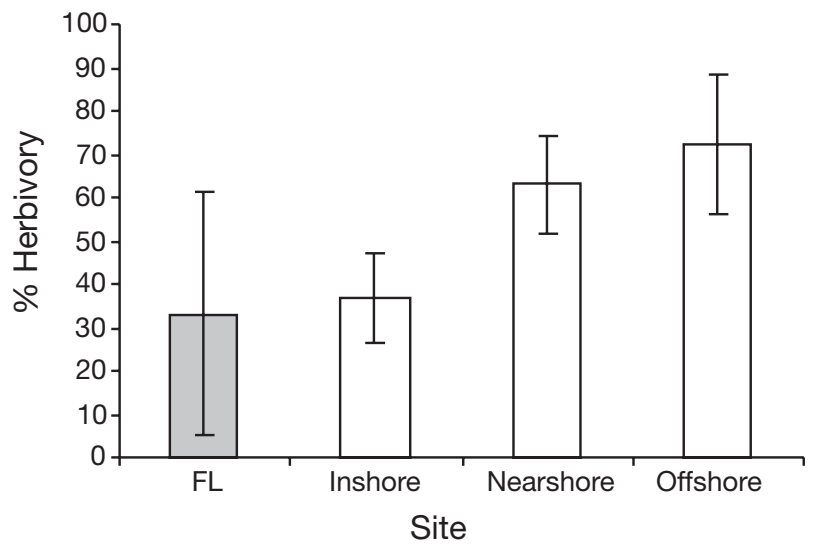

Fig. 5. Thalassia testudinum. Estimates of grazing intensity (mean $\pm \mathrm{SE}$ ) as indicated by the percentage of haphazardly collected blades possessing parrotfish bite scars. Florida Keys (FL) data (grey bar): Kirsch et al. (2002); all other data (white bars) from Bermuda platform, 2005 (present study)

\section{DISCUSSION}

Field assessments from 2004, high resolution maps from 1997 aerial photographs, and studies of aerial images from 1962 to 1997 (Ward 1999) corroborate that the total area of inshore and nearshore seagrass meadows has tended to remain relatively constant in Bermuda, even though the extent of individual meadows has varied over time. In stark contrast, a recent and widespread decline in seagrass meadows in the lagoon and around the sandy inner rim of the reef platform has resulted in a significant reduction in the number and area of seagrass meadows in Bermuda. Of a total of $\sim 900$ ha of lagoon and offshore meadows determined in 1997, 22 meadows representing $\sim 475$ ha were either reduced to sandy areas with dead and decaying rhizomes, or had only very sparsely distributed shoots of Thalassia testudinum, Syringodium filiforme or Halodule wrightii by 2004 (Fig. 2).

Of the seagrass meadows that have experienced mass declines globally, $70 \%$ were affected by human-induced damage, including coastal development, physical impacts, anthropogenic pollutants and fertilizers, disease, high water temperatures, and anoxic sediments (Duarte 2002). These same disturbance agents have been documented within the inshore and nearshore seagrass habitats of Bermuda, and include anthropogenically-enhanced nutrients (von Bodungen et al. 1982, Jickells et al. 1986, McGlathery 1995, Jensen et al. 1998), chemical pollution (Burns et al. 1990, Owen et al. 2002), physical damage by moorings, dredging, boat propellers, and increased sedimentation (von Bodungen et al. 1982, but see Ward 1999). 
In contrast to inshore and nearshore meadows, the lagoonal and offshore meadows in Bermuda have not been exposed to any obvious anthropogenic disturbance. Sedimentation and turbidity caused by ship traffic was low in the 1990s (Smith 1998), because large vessels rarely used the channel located farther from shore prior to 2005. Anchoring is uncommon and permanent moorings are illegal in lagoonal and offshore meadows. The meadows are too deep to be hit by boats or propellers and are legally protected from dredging. Additionally, water-column concentrations of nitrogen and phosphorous (von Bodungen et al. 1982) and of measured pollutants (Burns et al. 1990, Owen et al. 2002) have been consistently low at sampling sites located over $1 \mathrm{~km}$ from shore over the past 3 decades.

Although the causes of the recent decline and factors preventing re-establishment of the lagoonal and offshore meadows cannot be determined from the data available at this time, the broad spatial extent of the event across the platform (Fig. 2) suggests that factors operating over large spatial scales, such as region-wide climate, water-quality, and national environmental management practices played a predominant role in the change. Additionally, there is some indication that these large-scale, top-down and bottom-up factors may have interacted to negatively affect the seagrass meadows away from shore. Below we discuss some of the factors we believe may have played a synergistic role in the mass decline event in Bermuda, so as to provide a framework for future research and monitoring.

A scenario for the decline in the meadows is that chronically low primary productivity of Bermuda seagrasses (CARICOMP 2004), which are at the northern limit for most local species, combined with a number of other factors to cause the changes in seagrass condition in the period documented. Factors determining low productivity in these seagrass meadows are cool water temperatures and short day lengths in winter at $32^{\circ} \mathrm{N}$ latitude, as well as the low nutrient availability of the surrounding waters of the oligotrophic Western North Atlantic (Bates 2001). This low productivity, combined with herbivory by parrotfish, turtles and snails, could result in a very low standing crop and total photosynthetic surface area. Additionally, the entire system may have been critically aggravated by colder-than-average winter seawater temperatures in 1996 (Cohen et al. 2004), which coincided with changes in regional climate indicated by a switch from a positive to negative North Atlantic Oscillation (NAO) index in the same year (Visbeck et al. 2001).

In this scenario, a number of questions stand out. (1) Is seagrass productivity chronically low in Bermuda? (2) Is productivity limited by light, temperature or nutrients in Bermuda? (3) Are herbivory rates high in Bermuda? (4) Are these factors more extreme in off- shore than in inshore meadows? (5) What was the pattern and rate of seagrass mortality underlying the observed decline?

Some existing reports provide data toward testing this scenario for the change in seagrass habitat in Bermuda. Productivity rates of the Bermuda CARICOMP sites were among the lowest of all sites in the program (Smith 1998, CARICOMP 2004) and-owing to Bermuda's northern location - winter light availability and temperatures are low (even though the contribution of each to limiting seagrass productivity in Bermuda has yet to be demonstrated). Nutrient levels in lagoonal waters have historically been much lower than in inshore and nearshore sites (von Bodungen et al. 1982); however, no new data for the past $15 \mathrm{yr}$ has been published. Although nutrient levels in the interstitial water of offshore seagrass meadows have yet to be assessed, nearshore Thalassia testudinum meadows have demonstrated nutrient levels comparable to those seen in the Caribbean and Florida (Barnes 1994). Bermuda has dense populations of herbivorous parrotfishes (Luckhurst 1996) and green turtles (Meylan et al. 1998), both of which are legally protected from harvesting and culturally shunned as food country-wide. Total frequency of parrotfish herbivory in Bermuda is roughly double that measured in the Florida Keys (Kirsch et al. 2002; Fig. 5).

Unfortunately, although inshore water quality data has been collected across the islands over the past 3 decades (von Bodungen et al. 1982), there are no comparable large-scale and long-term oceanographic monitoring projects in progress in lagoonal or offshore sites. Also, studies of seagrass in Bermuda prior to 2004 were focused on specific small-scale locations, were only continued for short time periods, and were not designed to address marine habitat management issues for the entire reef platform. Such information is now needed if we are to determine and manage the environmental and ecological factors that impact seagrass habitat in Bermuda.

The unexpected demise of a substantial proportion of the total area of seagrass across the outer platform indicates that the Bermuda region is now affected by processes that encompass large spatial scales. Recently, other marine ecosystems in the Caribbean have experienced similar increases in the scales over which ecological changes have occurred. (e.g. Aronson et al. 2002), indicating that the entire sub-tropical and tropical Atlantic may be experiencing an unprecedented modification of marine ecosystems. The extent of the Bermuda event highlights the need for broadscale (synoptic) and long-term (permanent) multidisciplinary research and management strategies for the marine environment. The long-term effect of the loss of a substantial proportion of Bermuda's critical seagrass habitat should be a matter of both local and regional concern. 
Acknowledgments. A grant from the Bermuda Ministry of the Environment, Environmental Grant Scheme to K.A.C. provided support for the initiation of collaborative studies on Bermuda seagrasses. BREAM is supported by a grant from the Department of Conservation Services and Mr. \& Mrs. Anthony Jonklaas of the Kenridge Fund. The Bermuda CARICOMP study was supported by the J. D. and K. T. McArthur Foundation, and by grants to the Bermuda Biological Station for Research (BBSR) from the Bermuda Ministry of the Environment. S.R.S. thanks A. H. Knap, Director of BBSR, for supporting CARICOMP. N. Nelson, University of California, Santa Barbara, provided valuable collaborative support to M.V. and advice and information to K.A.C. We thank the many diligent research assistants, student interns, and volunteers for assisting with the various seagrass projects that contributed to this compilation. This is contribution No. 95 of the Bermuda Biodiversity Project (BBP), Bermuda Aquarium, Natural History Museum and Zoo, contribution No. 1698 of the Bermuda Institute of Ocean Sciences, and contribution No. 345 of the Southeast Environmental Research Center at Florida International University.

\section{LITERATURE CITED}

Anderson C, DeSilva H, Furbert J, Glasspool A, Rodrigues L, Sterrer W, Ward J (2001) Bermuda Biodiversity Country Study. Bermuda Biodiversity Project, Bermuda Aquarium, Museum and Zoo, Flatts

Aronson RB, Macintyre IG, Precht WF, Murdoch TJT, Wapnick CM (2002) The expanding scale of species turnover events in coral reefs in Belize. Ecol Monogr 72:233-249

Barnes PAG (1994) Eco-physiology of the endosymbiontbearing lucinid bivalve, Codakia orbiculata. PhD thesis, University of Plymouth

Bates NR (2001) Interannual changes of oceanic $\mathrm{CO}_{2}$ and biogeochemical properties in the Western North Atlantic subtropical gyre. Deep-Sea Res II 48:1507-1528

Berg JC Jr, Ward JAD, Luckhurst B, Nisbet K, Couper F (1992) Observations of breeding aggregations of the queen conch, Strombus gigas. Proc Gulf Caribb Fish Inst 42:161-171

Bermuda Zoological Society (1997) Bermuda from the air. Bermuda Zoological Society, Flatts

Burns KA, Ehrhardt MG, MacPherson J, Tierney JA, Kananen G, Connelly D (1990) Organic and trace metal contaminants in sediments, seawater and organisms from two Bermudan harbours. J Exp Mar Biol Ecol 138:9-34

CARICOMP (2004) CARICOMP - Caribbean Coastal Marine Productivity Program: 1993-2000. Florida Institute of Oceanography, St. Petersburg

Cohen AL, Smith SR, McCartney MS, van Etten J (2004) How brain corals record climate: an integration of skeletal structure, growth and chemistry of Diploria labyrinthiformis from Bermuda. Mar Ecol Prog Ser 271:147-158

Duarte CM (2002) The future of seagrass meadows. Environ Conserv 29:192-206

Durako MJ, Kunzelman JI, Kenworthy WJ, Hammerstrom KK (2003) Depth-related variability in the photobiology of two

Editorial responsibility: Kenneth Heck (Contributing Editor), Dauphin Island, Alabama, USA populations of Halophila johnsonii and Halophila decipiens. Mar Biol 142:1219-1228

Evans CR, Evans AJ (1995) Fishery ecology and spiny lobsters Panulirus argus and Panulirus guttatus (Latreille) at Bermuda: estimates of sustainable yields and observations on trends in abundance. Fish Res 24: $113-128$

Glasspool AF (1994) Larval distribution, population structure and gene flow in Bermuda's reef fish. PhD thesis, University College of North Wales, Menai Bridge

Jensen HS, McGlathery KJ, Marino R, Howarth RW (1998) Forms and availability of sediment phosphorous in carbonate sand of Bermuda seagrass meadows. Limnol Oceanogr 43:799-810

Jickells TD, Knap AH, Smith SR (1986) Trace metal and nutrient fluxes through the Bermuda inshore waters. Rapp p-v Reun Cons Int Explor Mar 186:251-262

Kirsch KD, Valentine JF, Heck KL (2002) Parrotfish grazing on turtlegrass Thalassia testudinum: evidence for the importance of seagrass consumption in the food web dynamics of the Florida Keys National Marine Sanctuary. Mar Ecol Prog Ser 227:71-85

Larkum AWD, Orth RJ, Duarte CM (2006) Seagrasses: biology, ecology and conservation. Springer, New York

Luckhurst BE (1996) A fishery independent assessment of Bermuda's coral reef fish stocks following the fish pot ban - a progress report. Proc Gulf Caribb Fish Inst 46: 309-323

McGlathery K (1995) Nutrient and grazing influences on a subtropical seagrass community. Mar Ecol Prog Ser 122:239-25

Meylan P, Meylan A, Gray J (1998) Density and biomass of green turtles in developmental habitats in Bermuda. In: Epperly SP, Braun J (eds) Proc 17th Annu Symp Sea Turtle Biol Conserv. NOAA Tech Mem NMFS-SEPFSC 415:68, Miami, FL

Owen R, Knap A, Toaspern M, Carbery K (2002) Inhibition of coral photosynthesis by the antifouling herbicide Irgarol 1051. Mar Pollut Bull 44:623-632

Smith SR (1998) Bermuda. In: Kjerfve B (ed) CARICOMP Caribbean coral reef, seagrass and mangrove sites. UNESCO, Paris, p 247-257

South RL (1983) A note on two communities of seagrass and rhizophytic algae in Bermuda. Bot Mar 26:243-248

Thayer GW, Kenworthy WJ, Fonseca MS (1984) The ecology of eelgrass meadows of the Atlantic coast: a community profile. US Fisheries and Wildlife Services Report FWS/ OBS-84/02. US Fisheries and Wildlife Services, Washington, DC

Visbeck MH, Hurrell JW, Polvani L, Cullen HM (2001) The North Atlantic Oscillation: past, present, and future. Proc Natl Acad Sci USA 98:12876-12877

von Bodungen B, Jickells TD, Smith SR, Ward JAD, Hillier GB (1982) The Bermuda marine environment. III. The final report of the Bermuda Inshore Waters Investigations 1975-1980. Bermuda Biological Station Spec Publ No.18, St. George's

Ward JAD (1999) Bermuda's coastal seagrass beds as habitats for fish. MSc thesis, University of Glasgow

Submitted: April 4, 2005; Accepted: September 13, 2006

Proofs received from author(s): May 11, 2007 